Génét. Sél. Evol., 1984, 16 (1), 121-126

\title{
Note
}

\section{The effect on egg laying of crosses made in Tribolium castaneum between lines selected for high and low responsiveness to conditioned medium}

\author{
Batia LAVIE $\left({ }^{*}\right)$, U. RITTE and R. MOAV \\ Department of Genetics, The Hebrew University of Jerusalem \\ 91904 Jerusalem, Israel
}

\begin{abstract}
Summary
Tribolium castaneum lines selected for high (HR) and low (LR) responsiveness of egg production to the conditioning of the medium were employed in crosses designed to determine the direction of dominance for responsiveness. In all three populations, the cross between HR females with LR males yielded responsiveness values as high or even higher than the HR line, indicating dominance for high responsiveness. The values of responsiveness encountered for the reciprocal crosses, ranging from lower than the LR line to higher than the HR line, suggest that more than one major gene is accounting for variation in responsiveness, and that maternal effect may also be involved.
\end{abstract}

Key words : Tribolium castaneum, egg production, conditioned medium.

\begin{abstract}
Résumé
Incidence sur la ponte de Tribolium castaneum $d u$ croisement entre lignées sélectionnées pour des sensibilités de réponse forte et faible à un milieu dégradé
\end{abstract}

Des lignées de Tribolium castaneum sélectionnées sur la ponte pour une sensibilité de réponse haute (HR) et basse (LR) à un milieu dégradé ont été croisées pour étudier la dominance de cette caractéristique. Dans les 3 populations étudiées, le croisement entre femelles HR et mâles LR procure une sensibilité de réponse supérieure ou égale à celle observée dans la lignée HR indiquant par-là, la dominance d'une forte sensibilité de réponse. Les valeurs de sensibilité enregistrées sur les croisements réciproques qui se situent

${ }^{*}$ ) Present Address : Institute of Evolution, Haifa University, 31999 Haifa, Israel. 
en dessous de celle de la lignée LR ou au-dessus de HR laissent à penser que plus d'un gène majeur se trouve impliqué dans le déterminisme de la sensibilité et que des effets maternels peuvent également intervenir.

Mots clés : Tribolium castaneum, ponte, milieu dégradé.

Several studies have shown that in addition to the control of the level of a quantitative trait, there may be an independent control of the responsiveness of this trait to the environment. So far, the traits and organisms involved in these studies have been growth rate in Schizophyllum commune (JINKS \& CONNOLLY, 1973, 1975 ; CoNNOLLY \& JINKs, 1975), final height and flowering time in Nicotiana rustica (PERKINS \& JINKS, 1968, 1971, 1973 ; BRUMPTON et al., 1977 ; Jinks et al., 1977 ; BougheY \& JINKS, 1978), and egg production in Tribolium castaneum (LAVIE et al., 1978; BoLET et al., 1979).

If the independent control of the responsiveness of a trait is true, it should be included in selection programs. In many cases, for example, selection for low responsiveness should be more important than selection for an optimal level of the trait.

A major problem in the recognition of responsiveness is a knowledge of its genetic control, which should be independent of the genetic control of the trait itself. One solution to this problem is to use $\beta^{\prime}$, which is derived from the analysis of genotype $\times$ environment interaction. The derivation of $\beta^{\prime}$ is as follows (MOAV \& WolHFARTH, 1974) : in the conventional linear model, the performance of the $\mathrm{j}^{\text {th }}$ genotype on the $i^{\text {th }}$ environment, $g_{i j}$, is partitioned into the average environmental effect $\left(a_{i}\right)$, the average genetic effect $\left(g_{i}\right)$, and a genotype $\times$ environment interaction $\left(\mathrm{ga}_{\mathrm{ij}}\right)$ :

$$
g_{i j}=a_{i}+g_{i}+g a_{i j}
$$

Bucio Alanis (1966) partitioned the interaction term into a linear function of the environmental deviation $\left(\beta_{\mathrm{j}} \mathrm{a}_{\mathrm{i}}\right)$ and a residual independent component $\left(\delta_{\mathrm{ij}}\right)$, so that the equation gets the form :

$$
g_{i j}=\left(1+\beta_{j}\right) a_{i}+g_{i}+\delta_{i j}
$$

Moav \& Wohlfarth (1974) further divided $\beta_{j}$ into $s_{j}$, which is the correlation of the inter-environment differences on $g_{j}$ (not a true genetic interaction), and $\boldsymbol{\beta}_{j}^{\prime}$ which is the specific responsiveness of genotype $j$ to environment $i$. $\beta_{j}^{\prime}$, which can serve as the unit of selection for responsiveness, can be calculated from the equation :

$$
g_{i j}=\left(1+\beta_{j}^{\prime}\right) a_{i}+g_{j}+s g_{j} a_{i}+\delta_{i j}
$$

In a previous publication (LAVIE et al., 1978) we presented results of a selection program which was based on $\beta^{\prime}$, and was carried out on high and low responsiveness of egg production in representatives of three wild populations of Tribolium castaneum in Israel (Jaffa, Rehovot and Beer-Sheva). In each population two selection lines - HR (High Responsiveness) and LR (Low Responsiveness) - were established. The responsiveness of egg production was measured by comparing the net fecundity (number of eggs recovered) by virgin females in three types of flour : fresh, mildlyconditioned and highly-conditioned. The use of virgin females was in line with YAMADA (1974), who showed that the genetic correlation between the egg laying of virgin and fecund females was 0.8, and Orozco \& Bell (1974), who showed that in a selection program for egg production, a large amount of «error variance » is removed if selection is based on virgins. 


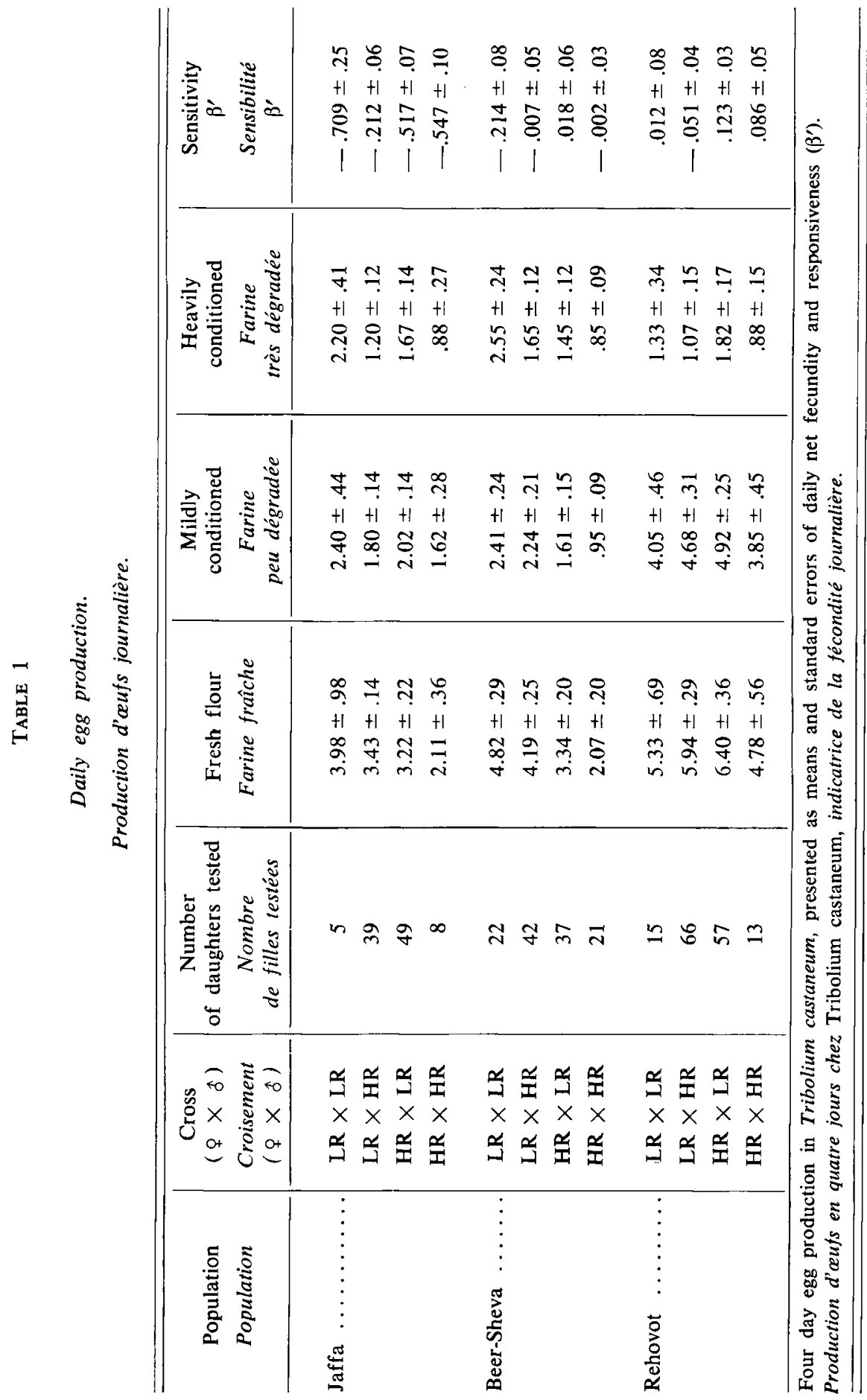


In the three populations, statistically significant differences between the $H R$ and the LR lines were obtained after one generation of selection, and these differences did hardly change in subsequent generations. It was concluded that (1) responsiveness for egg laying indeed has an independent genetic control, and (2) this control is caused by a small number of genes. The present note describes an additional aspect of this study, done in an attempt to increase our knowledge of the genetic basis of responsiveness.

After the sixth generation of selection, several females from each selection line were mated with males of the same line or of the other line of the same population. Four types of matings were thus created : $q$ LR $\times \delta$ LR ; $q$ LR $\times \delta \mathrm{HR}$; o $\mathrm{HR} \times \hat{\text { of }} \mathrm{LR} ;$ i $\mathrm{HR} \times$ of $\mathrm{HR}$. The responsiveness of the progeny of the various crosses ( 4 types in each wild population) was determined by measuring the net fecundity of virgin daughters in the 3 types of medium, and calculating $\beta^{\prime}$ for each female. The results of the various crosses are given in Table 1 .

The purpose of the different crosses was to find out dominance relationships, if they exist, between HR and LR. Although the results of each population should be looked upon independently of the other populations, a common feature of all the populations was that the response of the daughters of the $q \mathrm{HR} \times \delta \mathrm{LR}$ cross was equal to or higher than that of the $q \mathrm{HR} \times \hat{\sigma} \mathrm{HR}$ cross. This consistency was not shared by the daughters of the reciprocal cross ( $ᄋ$ LR $\times \hat{o} \mathbf{H R}$ ), which in one population showed a higher value of $\beta^{\prime}$ than that of the $q \mathrm{HR} \times \hat{\sigma} \mathrm{HR}$ cross, while in another population it showed a lower value than that of the $q$ LR $\times \hat{o} \mathbf{L R}$ cross.

Overall no definite conclusion can be obtained for the genetic control of responsiveness of egg laying (a similar result was obtained by BoLET et al., 1979), but the fact that the response of the $q \mathrm{HR} \times \hat{\delta} \mathrm{LR}$ daughters was the same as that of the daughters of the $q \mathrm{HR} \times \delta \mathrm{HR}$ cross may indicate that HR is dominant over LR (as was found by Perkins \& Jinks, 1971 and ConNolly \& Jinks, 1975). The difference between the populations, and the demonstration of dominance in only one of the two reciprocal crosses, suggest that responsiveness is controlled in different populations by different loci, that a maternal effect may be involved in the dominance relationship, and that a more complete understanding of the phenomenon should involve much larger samples.

Received January 17, 1983.

Accepted September 28, 1983.

\section{References}

Bolet G., Callego A., Orozco F., 1979. Déterminisme génétique de la ponte de femelles vierges de Tribolium castaneum en milieu standard et en milieu dégradé. Ann. Génét. Sél. Anim., 11, 251-266.

Bucio Alanis L., 1966. Environmental and genotype-environment components of variability. I. - Inbred lines. Heredity, 21, 387-397.

BougheY H., JinKs J.L., 1978. Joint selection for both extremes of mean performance and of sensitivity to macroenvironmental variable. III. - The determinants of sensitivity. Heredity, 40, 363-369. 
BRUMPtON R.J., BougheY H., JinKs J.L., 1977. Joint selection for both extremes of mean performance and environmental sensitivity to a macroenvironmental variable. I. - Family selection. Heredity, 38, 219-226.

ConNOLly V., JiNKs J.L., 1975. The genetical architecture of general and specific environmental sensitivity. Heredity, 35, 249-250.

Jinks J.L., Connolly V., 1973. Selection for specific and general response to environmental differences. Heredity, 30, 33-40.

JiNKs J.L., ConNolly V., 1975. Determination of environmental sensitivity of selection lines by the selection environments. Heredity, 34, 401-406.

Jinks J.L., JaYASEKara N.E.M., Boughey H., 1977. Joint selection for both extremes of mean performance and of sensitivity to a macroenvironmental variable. II. - Single seed descent. Heredity, 39, 345-355.

Lavie B., Ritte U., Moav R., 1978. The genetic basis of egg lay response to conditioned medium in the flour beetle, Tribolium castaneum. I. - Two-way selection. Theor. Appl. Genet.., 52, 193-199.

Moav R., Wohlfarth G., 1974. Magnification through competition of genetic differences in yield capacity in carp. Heredity, 33, 181-202.

Orozco F., Bell A.E., 1974. A genetic study of egg laying of Tribolium in optimal and stress environments. Can. J. Genet. Cytol., 16, 48-60.

Perkins J.M., Jinks J.L., 1968. Environmental and genotype-environmental components of variability. III. - Multiple lines and crosses. Heredity, 23, 339-356.

Perkins J.M., JinKs J.L., 1971. Specificity of the interaction of genotypes with contrasting environments. Heredity, 26, 463-474.

Perkins J.M., Jinks J.L., 1973. The assessment and specificity of environmental and genotype-environment components of variability. Heredity, 30, 111-126.

YAMADA Y., 1974. Tribolium as a biological model in quantitative genetics. 1st World Congress on Genetics applied to Livestock Production, Madrid, october 7-11, 1974, 1, 439-450, Garsi, Madrid. 